\title{
Metabolic Effects of Dietary Purine in Rats
}

\author{
Takako YoKozAwA, ${ }^{1}$ Hikokichi OURA, ${ }^{1}$ and Toshio OKADA ${ }^{2}$ \\ ${ }^{1}$ Department of Biochemistry, Research Institute for Wakan-Yaku, \\ Toyama Medical and Pharmaceutical University, \\ Sugitani, Toyama 930-01, Japan \\ ${ }^{2}$ Department of Pediatrics, Faculty of Medicine, \\ Toyama Medical and Pharmaceutical University, \\ Sugitani, Toyama 930-01, Japan
}

(Received March 26, 1982)

\begin{abstract}
Summary The effect of different dietary purines on the metabolism of serum and urinary uric acid, allantoin, creatinine, urea nitrogen and urea was examined in the rat. Experimental diets were synthetic and they were given ad libitum during a 6-day experimental period. The results were compared with the renal morphological changes.

The results obtained were as follows: Hypoxanthine, inosine, guanosine and guanine were readily converted to uric acid and allantoin, whereas adenine was metabolized quite differently from other purines. In particular, the intake of adenine exhibited a decrease of the uric acid excreted in the urine. Furthermore, an increase of creatinine, urea nitrogen and urea in the serum as well as a reduction in their urine excretion were observed in rats fed on the adenine diet. Adenine produced a nephrotoxic condition as reflected in the histological changes.

From these observations, it is concluded that although the administered purines are closely related structurally, they are metabolized in so many different ways that some of the metabolites, particularly of adenine, may cause a potential nephrotoxicity.
\end{abstract}

Key Words dietary purine, rat, uric acid, allantoin, creatinine, urea nitrogen, urea, morphological change

Previously published data from our laboratory on measuring the level of uric acid in the urine showed that oral purines yielded different amounts of uric acid (1). For example, feeding rats with a hypoxanthine diet caused a significant rise in the urinary output of uric acid. A similar pattern in urinary excretion of uric acid was obtained in rats fed on an adenosine or guanosine diet. On the contrary, the feed of an adenine diet exhibited a decrease in the amount of uric acid in the urine. Our data further suggested that the intake of adenine caused a significant increase in the

\footnotetext{
${ }^{1}$ 横澤隆子, 大浦彦吉, ${ }^{2}$ 岡田敏夫
} 
values of creatinine and urea nitrogen of the serum, indicating an impairment of the renal function. However, these observations were not obtained in rats fed on hypoxanthine, adenosine, guanosine, inosine, or guanine diets (2).

Although a considerable amount of information has been gathered on the metabolic effect of individual purines in rats, little is known about the mechanisms which produce different responses. To investigate this problem, we examined systematically the influence of dietary purines on uric acid, allantoin, creatinine, urea nitrogen and urea in the serum and urine. This report also describes renal histological changes produced by adenine feeding. From the results, the mode of action of individual purines is discussed.

\section{MATERIALS AND METHODS}

Animals and diet. Male rats of the Wistar strain, initially weighing 90-100 g, were placed in a metabolic chamber under a conventional lighting regimen with a dark-night period. The animals were fed on commercial feeds (CLEA Japan Inc., Tokyo, type CE-2) for one week after arrival. They were then divided into 7 groups of 5 animals each and fed ad libitum on a control or purine diet for 6 days. The control diet consisted of the following composition (in $100 \mathrm{~g}$ ): casein $18 \mathrm{~g}, \alpha$ cornstarch $57.9 \mathrm{~g}$, sucrose $15 \mathrm{~g}$, soybean oil $2 \mathrm{~g}$, salt mixture (3) $4 \mathrm{~g}$, vitamin mixture (3) $1 \mathrm{~g}$, cellulose powder $2 \mathrm{~g}$, and choline chloride $0.1 \mathrm{~g}$. To this control diet, purine was supplemented separately with $0.75 \%$ adenine, adenosine, guanine, guanosine, hypoxanthine, or inosine. The body weight, food intake, and water intake of each rat were recorded daily. During the experimental period, the urine was collected daily in a $50 \mathrm{ml}$ Erlenmeyer flask. On the 6th day on the experimental diet, rats were sacrificed by cutting the carotid artery and the blood was collected. The serum was separated by centrifugation immediately after collecting the blood.

Chemical analyses. Uric acid was determined by a modification of the method of Caraway (4); allantoin, by the method of Young and Conway (5); creatinine, by a modification of the method of Folin-Wu(6); urea nitrogen, using a commercial reagent ("Urea NB-Test Wako" obtained from Wako Pure Chemical Industries, Ltd., Osaka, Japan) based on the urease-indophenol method; urea, by the method of Archibald (7).

Histological studies. Kidneys were excised from each animal and fixed in $10 \%$ buffered neutral formalin. Paraffin-embedded sections were stained with haematoxylin and eosin.

\section{RESULTS}

The changes in body weight, food intake, water intake and urine volume during the experimental period are summarized in Table 1. Adenine markedly reduced the average body weight gain and food intake, and increased the urine volume. However, other purines produced no appreciable change in all items. 
Table 1. Body weight, food intake, $\mathrm{H}_{2} \mathrm{O}$ intake, and urine volume of rats fed on a $0.75 \%$ purine diet.

\begin{tabular}{lcccc}
\hline \multicolumn{1}{c}{ Diet } & $\begin{array}{c}\text { Changes in } \\
\text { body wt. } \\
\text { (g/6 days) }\end{array}$ & $\begin{array}{c}\text { Food intake } \\
\text { (g/day) }\end{array}$ & $\begin{array}{c}\mathrm{H}_{2} \mathrm{O} \text { intake } \\
\text { (ml/day) }\end{array}$ & $\begin{array}{c}\text { Urine volume } \\
\text { (ml/day) }\end{array}$ \\
\hline Control & $35.3 \pm 2.8$ & $15.2 \pm 1.6$ & $19.0 \pm 2.0$ & $10.2 \pm 1.0$ \\
Adenine & $-8.7 \pm 2.4^{\mathrm{c}}$ & $5.7 \pm 0.3^{\mathrm{b}}$ & $22.1 \pm 1.4$ & $16.5 \pm 1.7^{\mathrm{a}}$ \\
Adenosine & $31.3 \pm 1.5$ & $13.7 \pm 0.7$ & $19.2 \pm 0.5$ & $11.6 \pm 3.0$ \\
Guanine & $33.1 \pm 1.3$ & $16.1 \pm 0.8$ & $19.5 \pm 0.7$ & $11.7 \pm 1.3$ \\
Guanosine & $31.5 \pm 2.4$ & $15.8 \pm 0.6$ & $20.7 \pm 1.0$ & $11.9 \pm 0.7$ \\
Hypoxanthine & $33.4 \pm 3.3$ & $15.7 \pm 0.6$ & $21.0 \pm 2.1$ & $11.3 \pm 1.9$ \\
Inosine & $34.8 \pm 1.6$ & $14.9 \pm 0.7$ & $20.3 \pm 0.3$ & $11.1 \pm 0.4$ \\
\hline
\end{tabular}

Values are mean \pm SE of 5 rats. ${ }^{\text {a }}$ Significantly different from the value of rats fed on a control diet, $p<0.05,{ }^{\mathrm{b}} p<0.01,{ }^{\mathrm{c}} p<0.001$.

Table 2. Uric acid, allantoin, creatinine, and urea nitrogen in the serum of rats fed on a $0.75 \%$ purine diet.

\begin{tabular}{lcccc}
\hline \multicolumn{1}{c}{ Diet } & $\begin{array}{c}\text { Uric acid } \\
(\mathrm{mg} / 100 \mathrm{ml})\end{array}$ & $\begin{array}{c}\text { Allantoin } \\
(\mathrm{mg} / 100 \mathrm{ml})\end{array}$ & $\begin{array}{c}\text { Creatinine } \\
(\mathrm{mg} / 100 \mathrm{ml})\end{array}$ & $\begin{array}{c}\text { Urea-N } \\
(\mathrm{mg} / 100 \mathrm{ml})\end{array}$ \\
\hline Control & $1.98 \pm 0.14$ & $2.29 \pm 0.04$ & $0.82 \pm 0.02$ & $17.5 \pm 1.0$ \\
Adenine & $2.03 \pm 0.04$ & $6.75 \pm 0.30^{\mathrm{c}}$ & $1.31 \pm 0.01^{\mathrm{c}}$ & $41.7 \pm 2.0^{\mathrm{c}}$ \\
Adenosine & $1.78 \pm 0.09$ & $2.74 \pm 0.14^{\mathrm{a}}$ & $0.82 \pm 0.01$ & $19.1 \pm 0.1$ \\
Guanine & $1.88 \pm 0.10$ & $3.89 \pm 0.14^{\mathrm{c}}$ & $0.83 \pm 0.03$ & $18.7 \pm 0.2$ \\
Guanosine & $1.87 \pm 0.14$ & $3.36 \pm 0.22^{\mathrm{b}}$ & $0.83 \pm 0.03$ & $18.7 \pm 1.1$ \\
Hypoxanthine & $2.06 \pm 0.05$ & $4.34 \pm 0.13^{\mathrm{c}}$ & $0.87 \pm 0.03$ & $18.3 \pm 1.2$ \\
Inosine & $1.95 \pm 0.06$ & $3.48 \pm 0.03^{\mathrm{c}}$ & $0.88 \pm 0.04$ & $18.3 \pm 1.6$ \\
\hline
\end{tabular}

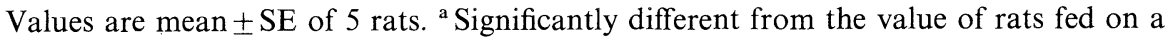
control diet, $p<0.05,{ }^{\mathrm{b}} p<0.01,{ }^{\mathrm{c}} p<0.001$.

Dietary adenine also increased the level of serum allantoin, as shown in Table 2 , being about 2.9 times higher in rats fed on an adenine diet than in those fed on a control diet. Although adenine increased the allantoin level most extensively among the six purines tested, hypoxanthine and guanine also produced a greater influence. Ranking purines with respect to the degree of increasing the level of serum allantoin, the following order was obtained: adenine $>$ hypoxanthine $>$ guanine $>$ inosine $=$ guanosine $>$ adenosine.

However, the values of serum uric acid for adenine, hypoxanthine, guanine, inosine, guanosine, and adenosine were almost the same (Table 2). On the other hand, dietary purine produced changes in urinary uric acid excretion. As shown in Table 3, administered purine caused a rise in the urinary excretion of uric acid, 
Table 3. Uric acid, allantoin, creatinine and urea in the urine of rats fed on a $0.75 \%$ purine diet.

\begin{tabular}{lcccc}
\hline \multicolumn{1}{c}{ Diet } & $\begin{array}{c}\text { Uric acid } \\
(\mathrm{mg} / \text { day })\end{array}$ & $\begin{array}{c}\text { Allantoin } \\
(\mathrm{mg} / \text { day })\end{array}$ & $\begin{array}{c}\text { Creatinine } \\
(\mathrm{mg} / \text { day })\end{array}$ & $\begin{array}{c}\text { Urea } \\
(\mathrm{mg} / \text { day })\end{array}$ \\
\hline Control & $2.23 \pm 0.26$ & $21.7 \pm 2.1$ & $3.46 \pm 0.20$ & $263 \pm 10$ \\
Adenine & $1.37 \pm 0.04^{\mathrm{a}}$ & $30.8 \pm 1.3^{\mathrm{a}}$ & $2.41 \pm 0.15^{\mathrm{b}}$ & $149 \pm 31^{\mathrm{b}}$ \\
Adenosine & $4.27 \pm 0.27^{\mathrm{b}}$ & $51.6 \pm 20^{\mathrm{c}}$ & $3.55 \pm 0.20$ & $241 \pm 19$ \\
Guanine & $3.18 \pm 0.12^{\mathrm{b}}$ & $64.7 \pm 7.1^{\mathrm{c}}$ & $3.84 \pm 0.13$ & $285 \pm 23$ \\
Guanosine & $4.24 \pm 0.15^{\mathrm{c}}$ & $76.8 \pm 2.6^{\mathrm{c}}$ & $3.86 \pm 0.18$ & $299 \pm 24$ \\
Hypoxanthine & $5.00 \pm 0.29^{\mathrm{c}}$ & $142.5 \pm 8.2^{\mathrm{c}}$ & $3.93 \pm 0.09^{\mathrm{a}}$ & $275 \pm 27$ \\
Inosine & $3.36 \pm 0.27^{\mathrm{b}}$ & $80.3 \pm 5.8^{\mathrm{c}}$ & $3.70 \pm 0.13$ & $260 \pm 29$ \\
\hline
\end{tabular}

Values are mean \pm SE of 5 rats. a Significantly different from the value of rats fed on a control diet, $p<0.05,{ }^{\mathrm{b}} p<0.01,{ }^{\mathrm{c}} p<0.001$.

except for adenine. Among the purines tested, hypoxanthine increased the urinary uric acid most extensively. On the contrary, feeding with an adenine diet showed a decrease of the uric acid excretion in the urine. In general, purines ranked in the following order: hypoxanthine $>$ adenosine $=$ guanosine $>$ inosine $=$ guanine $>$ adenine in the extent of urinary uric acid excretion.

Furthermore, the present report strongly confirmed that the urinary allantoin response was of different types according to the quality of dietary purine. As shown in Table 3, feeding of hypoxanthine to rats caused a significant rise in the urinary output of allantoin. In addition, a greater influence on the urinary excretion of allantoin was obtained in rats fed on inosine, guanosine, guanine, or adenosine diets. However, the value for creatinine, urea nitrogen or urea in the serum and urine, of hypoxanthine, inosine, guanosine, guanine, and adenosine, was almost the same except for adenine (Tables 2 and 3).

On the contrary, feeding rats on an adenine diet showed significant rises in creatinine and urea nitrogen in the serum (Table 2). In addition, a decrease was observed in the amounts of urinary uric acid, creatinine and urea in feeding with an adenine diet (Table 3). The kidneys were enlarged, pale grey in colour, and sometimes firm in consistency. The relative weight of the kidneys was about 1.5 times heavier in rats fed on an adenine diet than in those fed on a control diet. They were usually of normal shape but occasionally had a rough surface. In most kidneys numerous diminutive yellowish grains were visible in the cortex. Microscopically, the kidney tissue showed abnormalities in the proximal tubule cells. The epithelium was swollen and nuclear changes occurred frequently. Focally in the tubuli there was considerable cellular debris due to desquamation of epithelial cells. In addition, the administration of adenine caused a deposition of crystalline masses in the tubular lumina (Fig. 1). Pronounced tubular damage was seen. However, these changes were not seen in the kidneys of rats fed on adenosine, guanine, guanosine, 


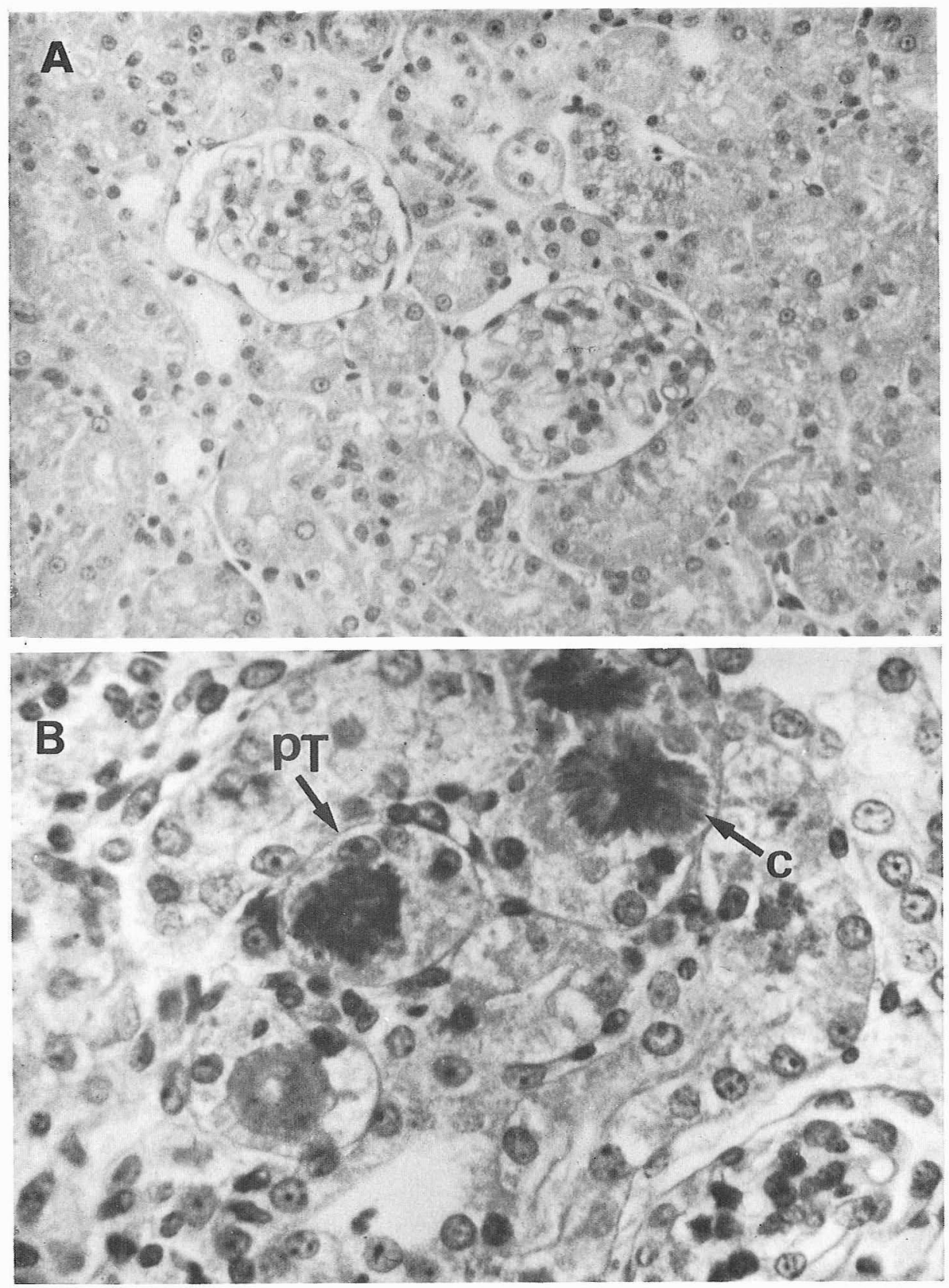

Fig. 1. Photomicrograph of kidney section of rats fed on a control diet $(\mathrm{A}: \times 200)$ and $0.75 \%$ adenine diet $(\mathrm{B}: \times 400)$. Haematoxylin-eosin stain. C, crystal; PT, proximal tubule. 
hypoxanthine, and inosine diets.

\section{DISCUSSION}

The previous report from our laboratory has shown that individual purines when given orally to rats yield different amounts of uric acid in the urine (1). In these studies, the purines ranked in the following order of the extent to which uric acid was excreted: hypoxanthine $>$ adenosine $=$ guanosine $>$ inosine $=$ guanine $>$ adenine. From these results, we have already suggested that adenine is metabolized quite differently from other purines in the body and have proposed that the purines except for adenine are more readily converted to uric acid. Our interpretation is supported by the known catabolic pathway of the purine base, i.e., adenine must be phosphorylated first to AMP prior to degradation (8), while hypoxanthine and guanine are directly converted to the end-product without phosphorylation (9). Furthermore, purine nucleoside is readily and passively absorbed and quantitatively converted to uric acid in everted gut sacs of rats and hamsters (10).

The present data, in addition to our previous work, confirmed that the urinary allantoin response was of different types according to the quality of a dietary purine. As shown in Table 3, hypoxanthine most extensively increased the urinary allantoin excretion. This greatest excretion by hypoxanthine compared to that of inosine, guanosine, guanine, or adenosine may be interpreted as being that hypoxanthine is most readily converted to uric acid as described above. Further studies showed that dietary adenine caused a significant rise in the serum allantoin level (Table 2). Although the adenine metabolism in experimental animals is not completely understood, Clifford and Story(11) showed that dietary adenine increased the activities of hepatic adenine phosphoribosyltransferase [EC 2.4.2.7], 5'-nucleotidase [EC 3.1.3.5] and adenosine deaminase [EC 3.5.4.4], and the concentration of free adenine in the liver. Furthermore, Ho et al.(12) described the absorption and metabolism of orally administered purines. Adenine was incorporated into tissues to a greater extent than was guanine, hypoxanthine, or xanthine in both fed and fasted rats. Orally-administered, radioactively-labeled adenine was mostly excreted as allantoin. Thus, the effect of dietary adenine may be understood as a result of the metabolic flow caused by the de novo biosynthesis of purine nucleotides and its catabolism to allantoin.

On the other hand, Bendich et al.(13) described that, especially in a supernormal concentration, adenine is converted by xanthine oxidase to 2,8-dihydroxyadenine, a urate analogue characterized by an extremely low solubility. Although 2,8-dihydroxyadenine is considered a minor metabolic product in the breakdown of adenine, Philips et al. (14), Shield et al. (15), and Lindblad et al. (16) reported that its relative insolubility makes it a potential source of renal damage. Considering these observations, adenine given orally in large doses may be nephrotoxic, attributable to 2,8-dihydroxyadenine. Indeed, feeding of an adenine diet to rats resulted in an increase of creatinine and urea nitrogen in the serum (Table 2). In addition, there 
were macroscopical renal changes such as swelling and pale grey surface colour. In most kidneys numerous diminutive yellowish grains were visible in the cortex. Microscopically, changes in the renal tissue were primarily a vacuolar degeneration of the tubular cells and a dilatation of the tubular lumina. Furthermore, formation of amorphous birefringent crystals was seen in the tubular lumina (Fig. 1). The results of our preliminary study have so far shown the accumulation of 2,8dihydroxyadenine (17). Accordingly, it has been assumed that the administration of adenine may cause an impairment of renal function by tubular obstruction with 2,8 dihydroxyadenine deposits.

Furthermore, our present data appeared to suggest that guanosine is more readily converted to uric acid plus allantoin than is adenosine (Tables 2 and 3). These differences may, in part, reflect metabolic pathways in purine degradation and reutilization. The fate of administered guanosine should be different from that of adenosine because the pathway leading from guanosine to GMP is not freely reversible in mammalian cells (18), thus guanosine might be converted to guanine and then be readily converted to xanthine by the action of guanase [EC 3.5.4.3], which is abundantly distributed in mammalian tissues. On the contrary, administered adenosine could be converted to inosine by the action of adenosine deaminase [EC 3.5.4.4] or to AMP by the action of adenosine kinase [EC 2.7.1.20]. From the concept of these different pathways, it is conceivable that dietary adenosine and guanosine compounds would yield a differential response.

Thus, the present study reveals that, although the administered purines themselves are closely related structurally, they are metabolized in different ways and produce different amounts of uric acid and allantoin: hypoxanthine, inosine, guanosine, and guanine are readily converted to uric acid and allantoin, whereas adenine, due to its unique metabolism, is metabolized quite differently from other purines. The nutritional influences through which these purines are metabolized may be related to several factors such as availability of substrates for de novo biosynthesis and reutilization, and enzyme induction. Savaiano et al.(19) demonstrated in his recent study that orally administered purines are more extensively excreted in the urine than are intravenously administered purines. These observations suggest that the gastrointestinal tract markedly influences the fate of dietary purines. Thus, a more precise understanding of the different responses of the body to individual purines is necessary for clarifying their metabolism.

\section{REFERENCES}

1) Yokozawa, T., Oura, H., Nakagawa, H., and Takemoto, K. (1981): Influence of dietary purine on the level of uric acid in the serum and urine. J. Jpn. Soc. Food Nutr., 34, 35-41.

2) Yokozawa, T., Oura, H., Nakagawa, H., and Fukuda, H. (1981): Metabolic effects of dietary adenine in rats. Nippon Nogeikagaku Kaishi (in Japanese), 55, 811-816.

3) Harper, A. E. (1959): Amino acid balance and imbalance. Part I. Dietary level of 
protein and amino acid imbalance. $J$. Nutr., 68, 405-424.

4) Takagi, Y. (1973): Uric acid, in Rinsyo Kagaku Bunseki (in Japanese), Vol. 2, ed. by Saito, M., Kitamura, M., and Niwa, M., Tokyo Kagaku Dojin, Tokyo, pp. 91-114.

5) Young, E. G., and Conway, C. F. (1942): On the estimation of allantoin by the RiminiSchryver reaction. J. Biol. Chem., 142, 839-853.

6) Nakamura, K. (1973): Creatine and creatinine, in Rinsyo Kagaku Bunseki (in Japanese), Vol. 2, ed. by Saito, M., Kitamura, M., and Niwa, M., Tokyo Kagaku Dojin, Tokyo, pp. 53-90.

7) Archibald, R. M. (1945): Colorimetric determination of urea. J. Biol. Chem., 157, $507-$ 518.

8) Flanks, J. G., Erwin, M. J., and Buchanan, J. M. (1957): Biosynthesis of the purines. XVI. The synthesis of adenosine 5'-phosphate and 5-amino-4-imidazolecarboxamide ribotide by a nucleotide pyrophosphorylase. J. Biol. Chem., 228, 201-213.

9) Ishii, K., and Green, H. (1973): Lethality of adenosine for cultured mammalian cells by interference with pyrimidine biosynthesis. J. Cell Sci., 13, 429-439.

10) Wilson, D. W., and Wilson, H. C. (1962): Studies in vitro of the digestion and absorption of purine ribonucleotides by the intestine. J. Biol. Chem., 237, 1643-1647.

11) Clifford, A. J., and Story, D. L. (1976): Levels of purines in foods and their metabolic effects in rats. J. Nutr., 106, 435-442.

12) Ho, C. Y., Miller, K. V., Savaiano, D. A., Crane, R. T., Ericson, K. A., and Clifford, A. J. (1979): Absorption and metabolism of orally administered purines in fed and fasted rats. J. Nutr., 109, 1377-1382.

13) Bendich, A., Brown, G. B., Philips, F. S., and Thiersch, J. B. (1950): The direct oxidation of adenine in vivo. J. Biol. Chem., 183, 267-277.

14) Philips, F. S., Thiersch, J. B., and Bendich, A. (1952): Adenine intoxication in relation to in vivo formation and deposition of 2,8-dioxyadenine in renal tubules. J. Pharmacol. Exp. Therap., 104, 20-30.

15) Shields, C. E., Lopas, H., and Birndorf, N. I. (1970): Investigation of nephrotoxic effects of adenine and its metabolic product, 2,8-dioxyadenine, on primates (Macaca irus). J. Clin. Pharmacol., 10, 316-322.

16) Lindblad, G., Jonsson, G., and Falk, J. (1973): Adenine toxicity: A three week intravenous study in dogs. Acta Pharmacol. et Toxicol., 32, 246-256.

17) Yokozawa, T., Oura, H., Nakagawa, H., and Okada, T., unpublished results.

18) Green, H., and Ishii, K. (1972): On the existence of a guanine nucleotide trap, the role of adenosine kinase and a possible cause of excessive purine production in mammalian cell. J. Cell Sci., 11, 173-177.

19) Savaiano, D. A., Ho, C. Y., and Clifford, A. J. (1980): Metabolism of orally and intravenously administered purines in rats. J. Nutr., 110, 1793-1804. 